\title{
Identification of Epoxide Functionalities
} in Protonated Monofunctional Analytes by Using Ion/Molecule Reactions and Collision-Activated Dissociation in Different Ion Trap Tandem Mass Spectrometers

\author{
Ryan J. Eismin, Mingkun Fu, Sonoeun Yem, Fanny Widjaja, Hilkka I. Kenttämaa \\ Department of Chemistry, Purdue University, 560 Oval Drive, West Lafayette, IN 47907, USA
}

\begin{abstract}
A mass spectrometric method has been delineated for the identification of the epoxide functionalities in unknown monofunctional analytes. This method utilizes gas-phase ion/ molecule reactions of protonated analytes with neutral trimethyl borate (TMB) followed by collision-activated dissociation (CAD) in an ion trapping mass spectrometer (tested for a Fouriertransform ion cyclotron resonance and a linear quadrupole ion trap). The ion/molecule reaction involves proton transfer from the protonated analyte to TMB, followed by addition of the analyte to TMB and elimination of methanol. Based on literature, this reaction allows the general identification of oxygen-containing analytes. Vinyl and phenyl epoxides can be differentiated from other oxygen-containing analytes, including other epoxides, based on the loss of a second methanol molecule upon CAD of the addition/methanol elimination product. The only other analytes found to undergo this elimination are some amides but they also lose $\mathrm{O}=\mathrm{B}-\mathrm{R}(\mathrm{R}=$ group bound to carbonyl), which allows their identification. On the other hand, other epoxides can be differentiated from vinyl and phenyl epoxides and from other monofunctional analytes based on the loss of $\left(\mathrm{CH}_{3} \mathrm{O}\right)_{2} \mathrm{BOH}$ or formation of protonated $\left(\mathrm{CH}_{3} \mathrm{O}\right)_{2} \mathrm{BOH}$ upon $\mathrm{CAD}$ of the addition/ methanol elimination product. For propylene oxide and 2,3-dimethyloxirane, the $\left(\mathrm{CH}_{3} \mathrm{O}\right)_{2} \mathrm{BOH}$ fragment is more basic than the hydrocarbon fragment, and the diagnostic ion $\left(\mathrm{CH}_{3} \mathrm{O}\right)_{2} \mathrm{BOH}_{2}{ }^{+}$is formed. These reactions involve opening of the epoxide ring. The only other analytes found to undergo $\left(\mathrm{CH}_{3} \mathrm{O}\right)_{2} \mathrm{BOH}$ elimination are carboxylic acids, but they can be differentiated from the rest based on several published ion/molecule reaction methods. Similar results were obtained in the Fourier-transform ion cyclotron resonance and linear quadrupole ion trap mass spectrometer.
\end{abstract}

Key words: Epoxides, vinyl epoxides, Phenyl epoxides, Ion-molecule reactions, Trimethyl borate, Functional-group selective

\section{Introduction}

nalytical methods that allow the rapid and accurate
identification of oxygen-containing functionalities in
unknown mixture components are important for many fields,

Correspondence to: Hilkka I. Kenttämaa; e-mail: hilkka@purdue.edu including the development of biofuels $[1,2]$. For example, lignin degradation products intended for conversion to biofuels require molecular level characterization before the best conversion method can be identified. Since removal of many oxygen-containing functionalities is needed to enhance the fuel's enthalpy, decrease viscosity, and stabilize the fuel [2], identification of oxygen-functionalities is of 
particular interest. Techniques that are currently used for these sorts of analyses include NMR, FT-IR, and X-ray crystallography $[3,4]$. These techniques are powerful but time-consuming, and often require large quantities of pure samples. Furthermore, they only yield information for the bulk when mixtures are analyzed. A method that allows the molecular-level characterization of complex mixtures is desirable.

Tandem mass spectrometry (MS/MS) is a technique well suited for obtaining structural information on unknown mixture components because it is fast, sensitive, does not require pure compounds, consumes a minimal amount of sample, and, most importantly, can provide a wealth of structural information $[5,6]$. MS/MS experiments typically involve protonation of all mixture components and isolation of each protonated analyte, one after the other, followed by their characterization by using collision-activated dissociation (CAD) [7, 8]. While powerful, this approach usually cannot be employed to unambiguously identify specific functional groups in unknown analytes. This is especially true for epoxides since protonated epoxides can rearrange to their more stable carbonyl isomers upon activation [9].

MS/MS experiments utilizing gas-phase ion/molecule reactions have been developed and used for the identification of functional groups in unknown analytes [10-15]. A variety of reagents can be used to probe different structural features. Furthermore, these experiments can be combined with CAD to provide additional structural information [10]. An example of such an approach includes the identification of phosphonium ions based on ion/molecule reactions with neutral epoxides or thioepoxides followed by CAD [16].

Most past work has focused on gas-phase ion/molecule reactions of neutral analytes with ionic reagents [17-19]. Fewer studies have explored the use of neutral reagents to identify functionalities in protonated analytes [10, 20-24]. However, this approach is needed for mixtures evaporated and ionized by the widely used electrospray ionization (ESI), atmospheric pressure chemical ionization (APCI), and matrix-assisted laser desorption/ionization (MALDI) methods. Previous research has demonstrated that ion/molecule reactions of protonated oxygen-containing analytes with trimethyl borate (TMB), followed by CAD, allow the identification and counting of different oxygen-containing functionalities, including hydroxyl, ether, ester, and amido groups $[17,20,22,25,26]$. The reaction sequence diagnostic for an oxygen-containing functionality involves proton transfer from the protonated analyte to $\mathrm{TMB}$, followed by addition of the analyte to the boron atom in TMB and (stepwise or concerted) elimination of methanol (Scheme 1). This reaction sequence leads to the derivatization of oxygen-containing functional groups of the analytes by the boron reagent. These products are easy to identify due to the isotope ratio of boron $\left(25 \%{ }^{10} \mathrm{~B}\right.$ relative to $\left.{ }^{11} \mathrm{~B}\right)$. Examination of the derivatized analytes by $\mathrm{CAD}$ or $\mathrm{H} / \mathrm{D}$ exchange allows for the identification of their functionalities.

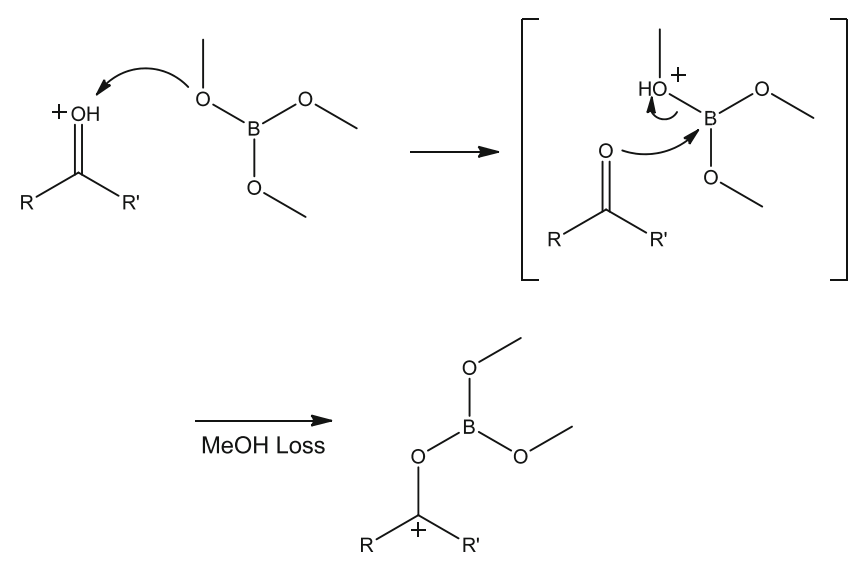

Scheme 1. Mechanism for elimination of methanol upon reaction of a protonated carbonyl compound with TMB

This study focuses on the distinction of protonated epoxides from other monofunctional oxygen-containing analytes by using ion/molecule reactions followed by CAD in a Fourier transform-ion cyclotron resonance (FT-ICR) mass spectrometer and a commercially available linear quadruple ion trap (LQIT) mass spectrometer that has been modified to allow the introduction of neutral reagents into the ion trap via an external mixing manifold [27]. The results demonstrate that $\mathrm{CAD}$ of the addition/methanol elimination products of protonated epoxides formed upon reaction with TMB not only allows distinction of epoxides from other analytes, but vinyl and phenyl epoxides can also be differentiated from other epoxides.

\section{Experimental}

The experiments were performed by using both an Extrel model FTMS 2001 FT-ICR mass spectrometer with a 3 Tesla superconducting magnet and a Thermo Scientific linear quadrupole ion trap (LQIT). Both instruments are described below.

\section{FT-ICR}

The FT-ICR contains a dual cell consisting of two differentially pumped, identical cubic 2 -in cells separated by a conductance limit plate. The conductance limit plate has a $2-\mathrm{mm}$ hole in the center for the transfer of ions from one side into the other. The conductance limit plate and the two end trapping plates were maintained at $+2.0 \mathrm{~V}$ unless otherwise specified.

Volatile samples were introduced into one cell region of the FT-ICR by using a Varian variable leak valve or a Thermo Scientific batch inlet system equipped with a variable leak valve. The analytes were ionized by electron bombardment and protonated by self-chemical ionization (self-CI). This was accomplished by allowing the molecular ions and the ionic fragments generated upon electron ionization (EI) $(25-70 \mathrm{eV}, 7 \mu \mathrm{A}, 0.1-1.0 \mathrm{~s})$ of the analyte to react with the neutral analyte molecules for a certain 
period of time (1-15 s). Nominal base pressure of the analytes in the cell varied between $3.9 \times 10^{-8}$ and $8.0 \times 10^{-8}$ Torr, as measured by an ion gauge. All the ions on the other side of the dual cell were removed prior to ion transfer by changing the remote trapping plate voltage from $+1.5 \mathrm{~V}$ to -10 $\mathrm{V}$ for $15 \mathrm{~ms}$. Protonated analytes were transferred into the other cell by grounding the conductance limit plate $(75-130 \mu \mathrm{s})$. Transferred ions were cooled for a period of $1 \mathrm{~s}$ by allowing IR emission and collisions with Ar pulsed into the cell (peak pressure in cell was about $10^{-5}$ Torr) [28]. The desired protonated analyte molecules were isolated by using a storedwaveform inverse Fourier transform [29, 30] (SWIFT) excitation pulse to eject all unwanted ions, and allowed to react with neutral TMB for a variable period of time (from 3 to $200 \mathrm{~s}$ ). The nominal pressure of TMB in the cell was between $1.7 \times 10^{-8}$ and $4.6 \times 10^{-8}$ Torr. Reaction products were further studied by isolating them and subjecting them to sustained off-resonance irradiated collision-activated dissociation (SORI-CAD) [31]. This experiment was carried out by subjecting the desired ions for $300 \mathrm{~ms}$ to an excitation rf-voltage pulse with an amplitude between 0.5 and $2.0 \mathrm{~V}$ while they underwent collisions with $\mathrm{Ar}$ (pulsed into the cell at peak pressure of about $10^{-5}$ Torr). The experiments utilized off-resonance excitation of the isolated ions at a frequency $\pm 1000 \mathrm{~Hz}$ off their cyclotron frequency. For detection, all ions were kinetically excited by a frequency chirp with a bandwidth of $4 \mathrm{MHz}$, amplitude of $25.0 \mathrm{~V}_{b-p}$ and a sweep rate of $3200 \mathrm{~Hz} / \mu \mathrm{s} ; 64 \mathrm{k}$ data points were recorded for each spectrum, and all spectra obtained are averages of at least 12 scans.

For each reaction time, a background spectrum was recorded by removing the ions of interest by SWIFT ejection prior to ion/molecule reaction or SORI-CAD. All the spectra were background corrected by subtracting a background spectrum from the reaction spectrum, as described previously [20-23].

During each ion/molecule reaction, TMB was present at a constant pressure, and in great excess relative to the ions of interest. Therefore, these reactions follow pseudo-first order kinetics. The reaction efficiencies (Eff. $=k_{\text {reaction }} / k_{\text {collision}}$; the fraction of ion/molecule collisions that result in the formation of products) were determined by measuring each ion/molecule reaction's (IM) rate and the rate of the highly exothermic proton transfer reaction (PT) between protonated methanol and the neutral reagent (both measurements were carried out in the same day). Assuming that this exothermic proton transfer reaction proceeds at the collision rate $\left(k_{\text {collision }}\right)$, the efficiencies of the ion/molecule reactions can be derived using Equation (1) [22]. This equation is based on the ratio of the slopes $\left(k_{\text {reaction }}[\mathrm{TMB}]=\right.$ slope (IM) and $k_{\text {collision }}[\mathrm{TMB}]=$ slope $(\mathrm{PT}) ;[\mathrm{TMB}]=\mathrm{TMB}$ concentration) of plots of the natural logarithm of the relative abundance of the reactant ion versus time, determined for the ion/molecule (IM) reaction and exothermic proton transfer (PT) reaction (thus eliminating the need to know [TMB]). In the equation, $M_{i}$ is the mass of the ion, $M_{n}$ is the mass of the neutral reagent, $\mathrm{M}_{(\mathrm{PT})}$ is the mass of methanol, $\mathrm{P}_{\mathrm{n}(\mathrm{IM})}$ is the pressure of the neutral reagent during the ion/molecule reaction, and $\mathrm{P}_{\mathrm{n}(\mathrm{PT})}$ is the pressure of the neutral reagent during the proton transfer reaction. The efficiencies were only determined in the FT-ICR due to the LQIT's low mass cut-off, which makes it impossible to examine the reaction of protonated methanol with TMB.

$$
\text { Efficiency }=\frac{\operatorname{Slope}(I M)}{\operatorname{Slope}(P T)}\left(\frac{M_{i}\left(M_{(P T)}+M_{n}\right)}{M_{(P T)}\left(M_{i}+M_{n}\right)}\right)^{\frac{1}{2}}\left(\frac{P_{n(P T)}}{P_{n}(I M)}\right) 100 \%
$$

\section{LQIT}

LQIT experiments were performed by using a Thermo Scientific LTQ linear quadruple ion trap equipped (LQIT) with an APCI source. Sample solutions were prepared at analyte concentrations ranging from 0.01 to $1 \mathrm{mg} / \mathrm{mL}\left(10^{-5}\right.$ to $\left.10^{-3} \mathrm{M}\right)$ in a $50 / 50(\mathrm{vol} / \mathrm{vol})$ solution of $\mathrm{H}_{2} \mathrm{O}$ and $\mathrm{CH}_{3} \mathrm{OH}$. An integrated syringe drive directly infused the solutions into the APCI source at a rate of $10-20 \mu \mathrm{L} / \mathrm{min}$. In the APCI source (operated in positive ion mode), the vaporizer and capillary temperatures were set at $450{ }^{\circ} \mathrm{C}$ and $200{ }^{\circ} \mathrm{C}$, respectively. The sheath gas $\left(\mathrm{N}_{2}\right)$ flow was maintained at about 10 arbitrary units. The voltages for the ion optics were optimized for each analyte by using the tune feature of the LTQ Tune Plus interface. The detection scan range was from $\mathrm{m} / \mathrm{z} 50$ to 500 .

A manifold like the one used here to allow the introduction of neutral reagents into the helium buffer gas line was first described by Gronert $[32,33]$. A diagram of the exact manifold used in this research was published by Habicht et al. [27]. TMB was introduced into the manifold via a syringe pump maintained at $20 \mu \mathrm{L} / \mathrm{h}$. A known amount of $\mathrm{He}(100-500 \mathrm{~mL} / \mathrm{min})$ was used to dilute TMB. The syringe port and surrounding area were heated to $\sim 70{ }^{\circ} \mathrm{C}$ to ensure evaporation of TMB. Before entering the trap, the $\mathrm{He} /$ reagent mixture was split using two Granville-Phillips leak valves, instead of the standard flow splitter. This allowed a better control over the concentration of the mixture introduced into the instrument. One leak valve was set to establish a helium pressure of $\sim 3$ mTorr in the ion trap by allowing $\sim 2 \mathrm{~mL} / \mathrm{min}$ of the mixture into the trap [34] while the other leak valve controlled the amount of flow diverted to waste. A typical pressure of TMB in the trap during the experiments ranged from $10^{-8}$ to $10^{-7}$ Torr, as given by $\mathrm{P}(\mathrm{He})[$ flow(TMB)/flow(He)][(MW(TMB)/MW $(\mathrm{He}))^{1 / 2}$ ] [33]. $\mathrm{P}(\mathrm{He})$ is the nominal helium buffer gas pressure in the ion trap, flow(TMB) is the molar flow rate of TMB, flow (He) is the molar flow rate of helium, MW (TMB) is the molecular weight of TMB, and $\mathrm{MW}(\mathrm{He})$ is the molecular weight of helium [33]. After the experiments were completed each day, the manifold was isolated from the instrument and placed under vacuum to remove any remaining reagent. 
Table 1. Product Ions ( $\mathrm{m} / \mathrm{z}$ Values And Branching Ratios) Formed In Reactions Between Various Protonated Analytes And TMB (MW 104), And SORICAD Fragments Of The Addition/elimination Products ( $m / z$ Values And Branching Ratios), Measured Previously [22] In An FT-ICR

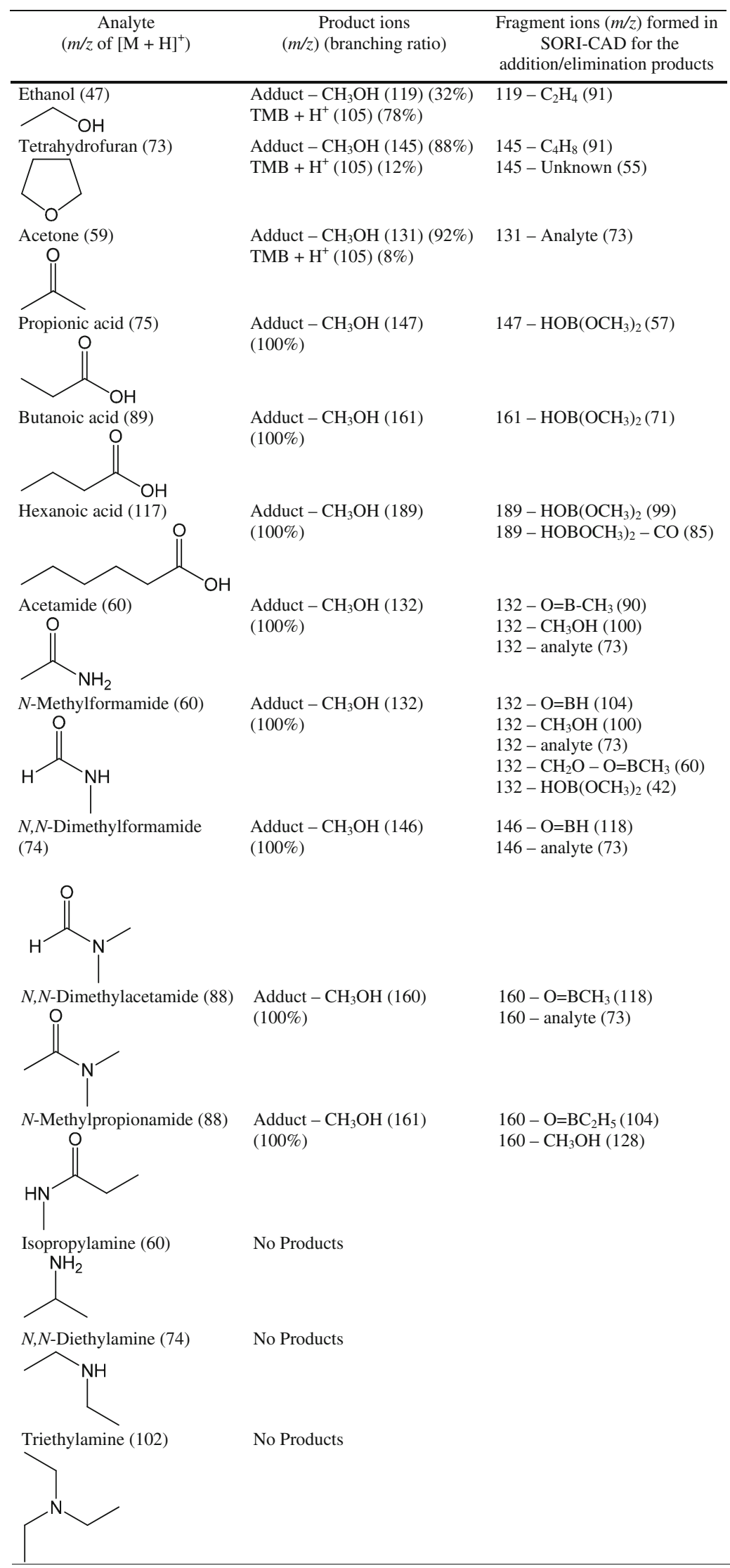


Xcalibur 2.0 (Thermo Scientific) software was used for data acquisition and processing. The advanced scan feature was used to isolate the analyte ions by using a $\mathrm{m} / \mathrm{z}$ window of 3-4 Th and a q value of 0.25 . After isolation, the ions were allowed to react with TMB from one $\mathrm{ms}$ up to $10 \mathrm{~s}$ (or until the reaction was compete) before all ions were ejected from the trap and detected. In the CAD experiments, the product ions were isolated by using a $\mathrm{m} / \mathrm{z}$ window of 3-4 units and kinetically excited by applying appropriate voltages to the trap (generally to achieve $10 \%-30 \%$ of the "normalized collision energy", as defined by the LTQ Tune Plus interface). The default activation time of $30 \mathrm{~ms}$ was used in all CAD experiments. All mass spectra shown are an average of at least 20 scans.

\section{Chemicals}

All chemicals were purchased from Sigma-Aldrich and used without further purification.

\section{Results and Discussion}

Ethyl vinyl ether was first tested for the general identification of epoxide functionalities since it was known to react with protonated cyclohexene oxide to form a diagnostic addition product in the gas phase [9]. Unfortunately, ethyl vinyl ether can also form an addition product with many protonated conjugated dienes. Further examination of several epoxides revealed that ethyl vinyl ether does not form an addition product with all protonated epoxides.

After above experiments, another reagent, TMB, was examined. This reagent is known to deprotonate protonated oxygen functionalities (but not, for example, nitrogen functionalities), followed by addition of the analyte to the boron center and elimination of methanol (Table 1), without causing rearrangement of the analyte $[17,18,22,25,26]$. Upon SORI-CAD, the methanol elimination products have been reported to yield structurally characteristic fragment ions for many oxygencontaining analytes (Table 1) [22, 35]. The same was

Table 2. Product Ions ( $\mathrm{m} / \mathrm{z}$ Values And Branching Ratios) Formed In Reactions Between Protonated Epoxides And TMB (MW 104), And SORI-CAD Fragment Ions Of The Addition/Elimination Products ( $\mathrm{m} / \mathrm{z}$ Values And Branching Ratios), Measured In An FT-ICR

\begin{tabular}{|c|c|c|}
\hline $\begin{array}{c}\text { Analyte } \\
\left(\mathrm{m} / \mathrm{z} \text { of }[\mathrm{M}+\mathrm{H}]^{+}\right)\end{array}$ & $\begin{array}{c}\text { Product ions } \\
(\mathrm{m} / \mathrm{z}) \text { (branching ratio) }\end{array}$ & $\begin{array}{l}\text { Fragment ions }(\mathrm{m} / \mathrm{z}) \text { (branching } \\
\text { ratio) formed upon SORI-CAD of } \\
\text { the addition/elimination product }\end{array}$ \\
\hline Butadiene monoxide (71) & Adduct $-\mathrm{CH}_{3} \mathrm{OH}(143)(100 \%)^{\mathrm{a}}$ & $143-\mathrm{CH}_{3} \mathrm{OH}(111)(100 \%)^{\mathrm{a}}$ \\
\hline Phenyloxirane (121) & Adduct $-\mathrm{CH}_{3} \mathrm{OH}(193)(100 \%)^{\mathrm{a}}$ & $\begin{array}{l}193-\mathrm{CH}_{3} \mathrm{OH}(161)(53 \%)^{\mathrm{a}} \\
193-\mathrm{CH}_{3} \mathrm{OH}-\mathrm{C}_{2} \mathrm{H}_{4} \mathrm{O}(117) \\
(47 \%)^{\mathrm{a}}\end{array}$ \\
\hline Phenylpropylene oxide (135) & Adduct $-\mathrm{CH}_{3} \mathrm{OH}(207)(100 \%)^{\mathrm{a}}$ & $207-\mathrm{CH}_{3} \mathrm{OH}(175)(100 \%)^{\mathrm{a}}$ \\
\hline Propylene oxide (59) & Adduct $-\mathrm{CH}_{3} \mathrm{OH}(131)(100 \%)^{\mathrm{a}}$ & $\begin{array}{l}131-\text { Analyte }(73)(77 \%)^{\mathrm{a}} \\
131-\mathrm{C}_{3} \mathrm{H}_{6}(\text { protonated } \\
\left.\mathrm{HOB}\left(\mathrm{OCH}_{3}\right)_{2}\right)(91)(23 \%)^{\mathrm{a}}\end{array}$ \\
\hline 2,3-Dimethyloxirane (73) & Adduct $-\mathrm{CH}_{3} \mathrm{OH}(145)(100 \%)^{\mathrm{a}}$ & $\begin{array}{l}145-\text { Analyte }(73)(54 \%)^{\mathrm{a}} \\
145-\mathrm{C}_{4} \mathrm{H}_{6}(\text { protonated } \\
\left.\mathrm{HOB}\left(\mathrm{OCH}_{3}\right)_{2}\right)(91)(26 \%)^{\mathrm{a}} \\
145-\mathrm{O}=\mathrm{BOCH}_{3}(87)(20 \%)\end{array}$ \\
\hline Cyclopentene oxide (85) & $\begin{array}{l}\text { Adduct }-\mathrm{CH}_{3} \mathrm{OH}(157)(75 \%)^{\mathrm{a}} \\
\mathrm{MH}^{+}-\mathrm{H}_{2} \mathrm{O}(67)(25 \%)\end{array}$ & $157-\mathrm{HOB}\left(\mathrm{OCH}_{3}\right)_{2}(67)(100 \%)$ \\
\hline Cyclohexene oxide (99) & $\begin{array}{l}\text { Adduct }-\mathrm{CH}_{3} \mathrm{OH}(171)(83 \%)^{\mathrm{a}} \\
\mathrm{MH}^{+}-\mathrm{H}_{2} \mathrm{O}(81)(17 \%)\end{array}$ & $171-\mathrm{HOB}\left(\mathrm{OCH}_{3}\right)_{2}(81)(100 \%)$ \\
\hline 1,2-Epoxy-5-hexene (99) & $\begin{array}{l}\text { Adduct }-\mathrm{CH}_{3} \mathrm{OH}(171)(82 \%)^{\mathrm{a}} \\
\text { Adduct }-\mathrm{CH}_{3} \mathrm{OH}-\mathrm{H}(170) \\
(18 \%)^{\mathrm{a}}\end{array}$ & $171-\mathrm{HOB}\left(\mathrm{OCH}_{3}\right)_{2}(81)(100 \%)$ \\
\hline
\end{tabular}

${ }^{\text {a } B o r o n ~ i s o t o p e s ~ v e r i f y ~ t h e ~ p r e s e n c e ~ o f ~ b o r o n ~}$ 
found to be true for protonated epoxides. The product ions formed from protonated vinyl and phenyl epoxides were found to undergo a characteristic elimination of a second methanol molecule upon SORI-CAD. On the other hand, the addition/methanol elimination products of all other epoxides studied either lose $\left(\mathrm{CH}_{3} \mathrm{O}\right)_{2} \mathrm{BOH}$ or form protonated $\left(\mathrm{CH}_{3} \mathrm{O}\right)_{2} \mathrm{BOH}$ upon $\mathrm{CAD}$. These findings are discussed in detail below.

\section{Results Obtained Using FT-ICR}

The results obtained by examining the reactions of several protonated epoxides with TMB in a FT-ICR mass spectrometer are summarized in Table 2. As expected, all protonated epoxides were found to react with TMB exclusively by addition/methanol elimination (Table 2; Figure 1). When the product ions were subjected to SORI-CAD, various fragmentation pathways were observed (Table 2). However, only the product ions formed from vinyl and phenyl epoxides underwent methanol elimination. Based on this elimination, vinyl and phenyl epoxides can be differentiated from other epoxides, including unsaturated ones. It must be noted here that the addition/methanol elimination products of some amides also undergo elimination of $\mathrm{CH}_{3} \mathrm{OH}$ upon SORI-CAD in FT-ICR
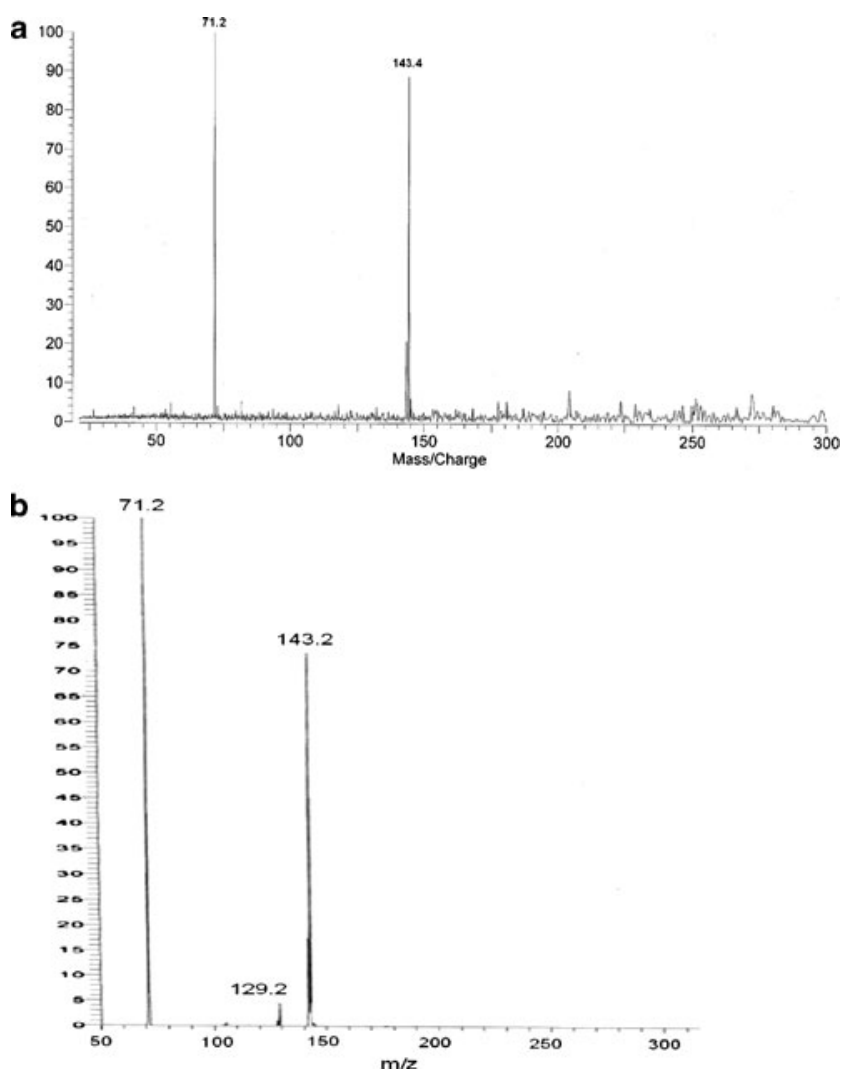

Figure 1. A mass spectrum measured (a) after $30 \mathrm{~s}$ reaction of protonated butadiene monoxide $(\mathrm{m} / \mathrm{z} 71)$ with TMB, leading to an addition/methanol elimination product $(\mathrm{m} / \mathrm{z} 143)$, in the FT-ICR, and (b) after $10 \mathrm{~ms}$ reaction in the LQIT
(Table 1) $[22,35]$ just like vinyl and phenyl epoxides. However, they also undergo elimination of $\mathrm{O}=\mathrm{B}-\mathrm{R}(\mathrm{R}=\mathrm{H}$, $\mathrm{CH}_{3}$ and $\mathrm{C}_{2} \mathrm{H}_{5}$ for formamide, acetamide, and propionamide, respectively), which allows the differentiation of amides from vinyl and phenyl epoxides. Hence, these results show that vinyl and phenyl epoxides can be distinguished from all other monofunctional analytes studied thus far. Some bifunctional analytes, however, show methanol elimination upon SORICAD of their addition/methanol elimination products [22]. Determination of the analytes' elemental compositions helps resolve this issue.

A possible mechanism for the elimination of the second methanol molecule from protonated vinyl and phenyl epoxides is shown in Scheme 2. The mechanism is supported by several pieces of evidence. First, the relative proton affinities [36] (PA) of TMB (195 kcal/mol), epoxides (from 185 for ethyleneoxide up to $203 \mathrm{kcal} / \mathrm{mol}$ for cyclohexeneoxide), and benzene $(179 \mathrm{kcal} / \mathrm{mol})$ strongly suggest that a facile proton transfer is the first reaction to take place. The solvation energy released upon formation of the reactant complex in a gas-phase collision is typically between 5 and $10 \mathrm{kcal} / \mathrm{mol}$, thus allowing proton transfers that are endothermic by $5-10 \mathrm{kcal} / \mathrm{mol}$. The second step, addition of the neutral epoxide to the boron atom, is supported by vast literature evidence that this commonly occurs for other oxygen-containing molecules, and is followed by elimination of methanol [17, 18, $22,25,26]$. The observation of elimination of methanol as well as ethylene oxide from the addition/methanol elimination product of protonated phenyl oxirane indicates that not only the epoxide oxygen but also the aromatic ring can act as the nucleophile in the addition reaction. The epoxide ring is not likely to open during this addition reaction since some of the addition/methanol elimination products of the epoxides fragment via the loss of the intact epoxide upon CAD (Tables 2 and 3). However, the following CAD event must lead to ring-opening since a second methanol molecule cannot be eliminated without a transfer of a proton to an oxygen atom bound to boron. The most likely proton to be transferred is the most acidic one, bound to the saturated carbon atom adjacent to the positively charged carbon atom, as indicated in Scheme 2. After this proton transfer occurs via a five-membered transition state, nucleophilic addition of the carbon-carbon double bond to the boron center is suggested, as nucleophilic addition to boron is known to induce elimination of methanol from protonated trimethyl borate. Support for the structure of the final product is obtained from CAD. For example, loss of $\mathrm{CH}_{3} \mathrm{OBH}_{2}$ and $\mathrm{CH}_{3} \mathrm{OB}=\mathrm{O}$ was observed (Scheme 3). The mechanism shown in Scheme 2 likely applies also to aromatic epoxides, and in this case involves the loss of aromaticity in the last step. However, a highly resonance stabilized cation is formed as the final production.

Other epoxides can be identified based on either the elimination of $\left(\mathrm{CH}_{3} \mathrm{O}\right)_{2} \mathrm{BOH}$ or formation of protonated 

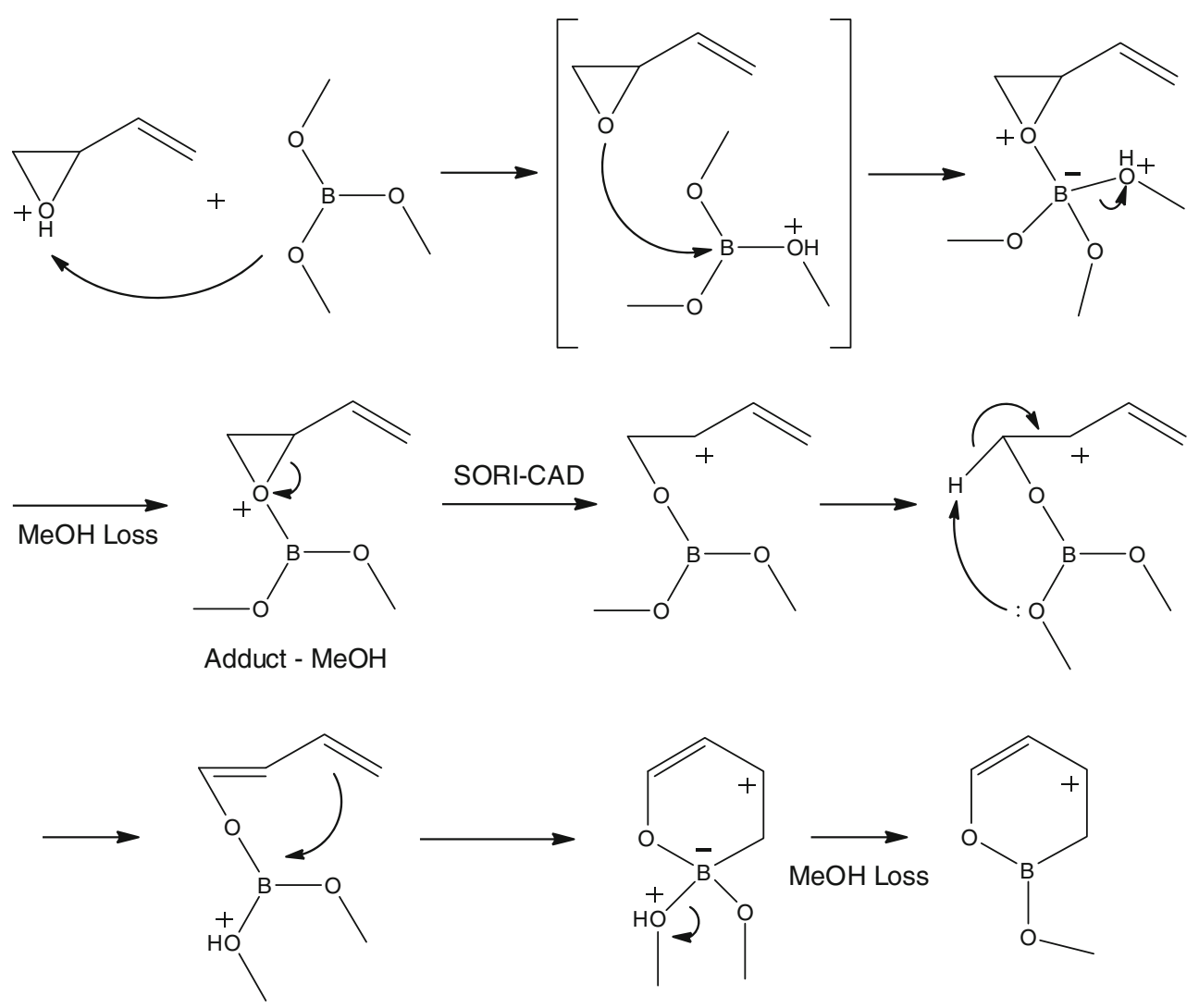

Scheme 2. Mechanism for elimination of two methanol molecules upon reaction of protonated butadiene monoxide with TMB

$\left(\mathrm{CH}_{3} \mathrm{O}\right)_{2} \mathrm{BOH}$ upon $\mathrm{CAD}$ of the addition/methanol elimination product (Table 2). The proposed mechanism (Scheme 4a) is supported by the same observations that support the mechanism shown in Scheme 2, with the exception of the last proton transfer step. There are two possibilities here: a 1,4-proton transfer to a methoxy oxygen from the cyclopentane carbon bound to the oxygen (that may lead to elimination of methanol and formation of a borenium ion) and a 1,4-proton transfer to the epoxide oxygen as shown in Scheme 4a (that may lead to elimination of $\left(\mathrm{CH}_{3} \mathrm{O}\right)_{2} \mathrm{BOH}$ or formation of protonated $\left.\left(\mathrm{CH}_{3} \mathrm{O}\right)_{2} \mathrm{BOH}\right)$. The proton transfer to the methoxy oxygen (Scheme 2) is sterically hindered for cyclohexene and -pentene oxides (Scheme 4a). Indeed, only the products from the other transfer are observed (Tables 2 and 3). For protonated propylene oxide and 2,3-dimethyloxirane, both proton transfers appear feasible. However, no methanol elimination was observed. Hence, the closeness of the (former) epoxide oxygen to a methyl group in these epoxides immediately after the epoxide ring-opening must lead to fast proton transfer (TS 2, Scheme 4b) before the molecule has time to rotate and form the other transition state (Scheme 2). These epoxides yield protonated $\left(\mathrm{CH}_{3} \mathrm{O}\right)_{2} \mathrm{BOH}(\mathrm{m} / z$ 91) as the final fragment ion, which indicates that the hydrocarbon fragments (propene and 2-butene) are less basic than $\left(\mathrm{CH}_{3} \mathrm{O}\right)_{2} \mathrm{BOH}$ for these small epoxides.
The only other analytes whose addition/methanol elimination products have been found [22] to fragment by elimination of $\left(\mathrm{CH}_{3} \mathrm{O}\right)_{2} \mathrm{BOH}$ are carboxylic acids (for a possible mechanism, see Scheme 5), but they can be differentiated from all other monofunctional oxygencontaining analytes by various other ion/molecule reactionbased approaches [20, 27].

The efficiencies of all the ion/molecule reactions studied here were measured by using a method described previously $[17,18,20-23]$. They were found to be high. For example, protonated 2,3-dimethyloxirane reacts with $\mathrm{TMB}$ at an efficiency of $72 \%$, protonated phenyloxirane at $63 \%$, protonated cyclohexene oxide at $32 \%$, and protonated propylene oxide at $74 \%$. These efficiencies suggest that these ion/molecule reactions are fast enough for practical applications.

\section{Result Obtained Using LQIT}

In order to explore the applicability of the above analytical method to other mass spectrometers, it was implemented to a LQIT. In this instrument, the epoxides were protonated in an atmospheric pressure chemical ionization (APCI) source, while protonation was carried out by chemical ionization in vacuum in the FT-ICR. Protonated epoxides were transferred from the APCI source into the trap where they were allowed to react with TMB. The same addition/methanol 
Table 3. Product Ions ( $m / z$ values and branching ratios) Formed in Reactions Between Protonated Epoxides and TMB (MW 104), and CAD Fragments of the Addition/Elimination Products ( $\mathrm{m} / \mathrm{z}$ values and branching ratios), Measured in an LQIT

\begin{tabular}{|c|c|c|}
\hline $\begin{array}{c}\text { Analyte } \\
\left(m / z \text { of }[\mathrm{M}+\mathrm{H}]^{+}\right)\end{array}$ & $\begin{array}{c}\text { Product ions } \\
(\mathrm{m} / \mathrm{z}) \text { (branching ratio) }\end{array}$ & $\begin{array}{l}\text { Fragment ions }(\mathrm{m} / \mathrm{z}) \text { (branching } \\
\text { ratio) formed in CAD of the } \\
\text { addition/elimination products }\end{array}$ \\
\hline onoxide (71) & $\begin{array}{l}\text { Adduct }-\mathrm{CH}_{3} \mathrm{OH}(143)(90 \%)^{\mathrm{a}} \\
\text { Adduct }-\mathrm{CH}_{3} \mathrm{OCH}_{3}(129)(10 \%)^{\mathrm{a}}\end{array}$ & $\begin{array}{l}143-\mathrm{CH}_{3} \mathrm{OH}(111)(56 \%)^{\mathrm{a}} \\
143-\text { analyte }(73)(18 \%)^{\mathrm{a}} \\
143-\mathrm{O}=\mathrm{BOCH}_{3}(85)(17 \%) \\
143-\mathrm{O}=\mathrm{BCH}_{3}(101)(9 \%)\end{array}$ \\
\hline Phenyloxi & $\begin{array}{l}\text { Adduct }-\mathrm{CH}_{3} \mathrm{OH}(193)(73 \%)^{\mathrm{a}} \\
\text { Adduct }-\mathrm{CH}_{2} \mathrm{O}-\mathrm{O}=\mathrm{BCH}_{3}(153) \\
(14 \%) \\
\text { Adduct }-\mathrm{CH}_{3} \mathrm{OCH}_{3}(179)(9 \%)^{\mathrm{a}} \\
\text { Adduct }-\mathrm{CH}_{3} \mathrm{OH}-\mathrm{CH}_{2} \mathrm{O}(163) \\
(4 \%)^{\mathrm{a}}\end{array}$ & $\begin{array}{l}193-\mathrm{CH}_{3} \mathrm{OH}(161)(79 \%)^{\mathrm{a}} \\
193-\mathrm{CH}_{3} \mathrm{OH}-\mathrm{C}_{2} \mathrm{H}_{4} \mathrm{O}(117) \\
(21 \%)^{\mathrm{a}}\end{array}$ \\
\hline ropylene oxide (135) & $\begin{array}{l}\text { Adduct }-\mathrm{CH}_{3} \mathrm{OH}(207)(71 \%)^{\mathrm{a}} \\
\text { Adduct }-\mathrm{CH}_{2} \mathrm{O}-\mathrm{O}=\mathrm{BCH}_{3}(167) \\
(14 \%) \\
\text { Adduct }-\mathrm{C}_{2} \mathrm{H}_{4} \mathrm{O}(163)(9 \%)^{\mathrm{a}} \\
\text { Adduct }-\mathrm{H}(238)(6 \%)^{\mathrm{a}}\end{array}$ & $\begin{array}{l}207-\mathrm{CH}_{3} \mathrm{OH}(175)(94 \%)^{\mathrm{a}} \\
207-\mathrm{CH}_{2} \mathrm{O}-\mathrm{O}=\mathrm{BCH}_{3} \\
(6 \%)\end{array}$ \\
\hline rane (73) & Adduct $-\mathrm{CH}_{3} \mathrm{OH}(145)(100 \%)^{\mathrm{a}}$ & $\begin{array}{l}145-\text { analyte }(73)(74 \%)^{\mathrm{a}} \\
145-\mathrm{C}_{3} \mathrm{H}_{6} \mathrm{O}(87)(14 \%)^{\mathrm{a}} \\
145-\mathrm{C}_{4} \mathrm{H}_{6}(91)(\text { protonated } \\
\left.\mathrm{HOB}\left(\mathrm{OCH}_{3}\right)_{2}\right)(12 \%)^{\mathrm{a}}\end{array}$ \\
\hline oxide (85) & $\begin{array}{l}\text { Adduct }-\mathrm{CH}_{3} \mathrm{OH}(157)(97 \%)^{\mathrm{a}} \\
\text { Adduct }-\mathrm{CH}_{3} \mathrm{OCH}_{3}(143)(3 \%)^{\mathrm{a}}\end{array}$ & $\begin{array}{l}157-\mathrm{HOB}\left(\mathrm{OCH}_{3}\right)_{2}(67)(65 \%) \\
157-\mathrm{C}_{5} \mathrm{H}_{6} \quad(91) \quad \text { (protonated } \\
\left.\mathrm{HOB}\left(\mathrm{OCH}_{3}\right)_{2}\right)(19 \%)^{\mathrm{a}} \\
157-\text { analyte }(73)(16 \%)^{\mathrm{a}}\end{array}$ \\
\hline oxide (99) & $\begin{array}{l}\text { Adduct }-\mathrm{CH}_{3} \mathrm{OH}(171)(90 \%)^{\mathrm{a}} \\
\text { Adduct }-\mathrm{CH}_{3} \mathrm{OCH}_{3}(157)(10 \%)^{\mathrm{a}}\end{array}$ & $171-\mathrm{HOB}\left(\mathrm{OCH}_{3}\right)_{2}(81)(100 \%)$ \\
\hline 1,2-Epoxy-5-hexene (99) & $\begin{array}{l}\text { Adduct }-\mathrm{CH}_{3} \mathrm{OH}(171)(93 \%)^{\mathrm{a}} \\
\text { Adduct }-\mathrm{CH}_{3} \mathrm{OCH}_{3}(157)(7 \%)^{\mathrm{a}}\end{array}$ & $171-\mathrm{HOB}\left(\mathrm{OCH}_{3}\right)_{2}(81)(100 \%)$ \\
\hline
\end{tabular}

${ }^{a}$ Boron isotopes verify the presence of boron

elimination products (Table 3; Figure 1) were observed as in the FT-ICR, as well as a few additional minor products not seen in the FT-ICR. An especially noteworthy reaction is the elimination of dimethyl ether from all epoxides except one, since this reaction has not been observed for any other analytes. Hence, this reaction provides further support for a preliminary identification of an epoxide functionality.

When the addition/methanol elimination product ions were subjected to CAD, those of vinyl and phenyl epoxides eliminated methanol, and those of the other epoxides either eliminated $\left(\mathrm{CH}_{3} \mathrm{O}\right)_{2} \mathrm{BOH}$ or formed protonated $\left(\mathrm{CH}_{3} \mathrm{O}\right)_{2}$ -

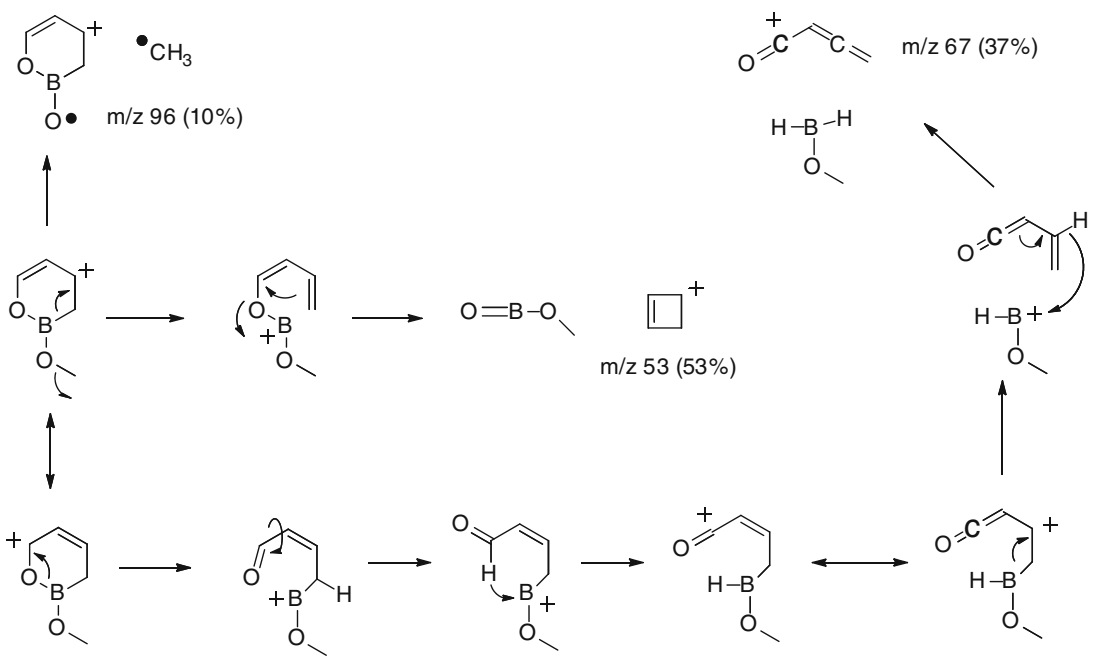

Scheme 3. Likely mechanisms for dissociation reactions of the final double methanol elimination product shown in Scheme 2 
a

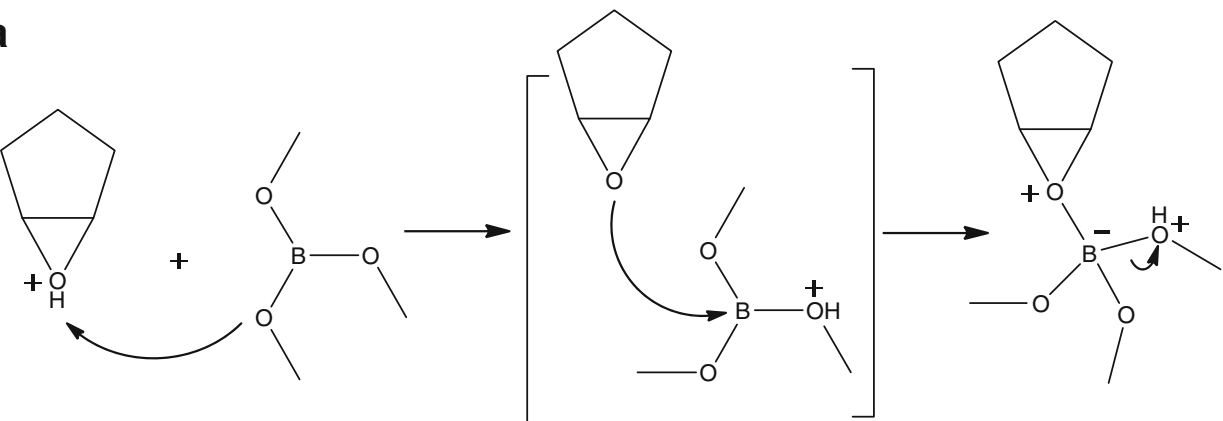

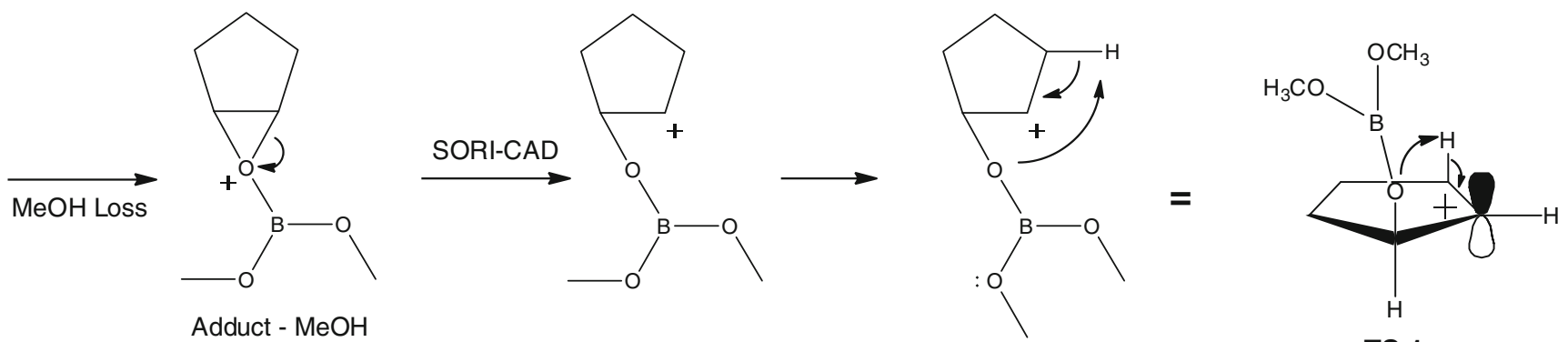

Adduct - $\mathrm{MeOH}$

TS 1<smiles>COB(OC)[C@@H]1C=C[C@@H]2CCC=C21</smiles>

b<smiles>COB(OC)OC1CCCC1</smiles>

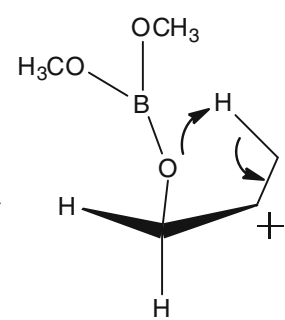

TS 2

Scheme 4. Mechanism for elimination of methanol and dimethyl borate upon reaction of a) protonated cyclopentene oxide and b) protonated 2,3-dimethyloxirane with $\mathrm{TMB}$
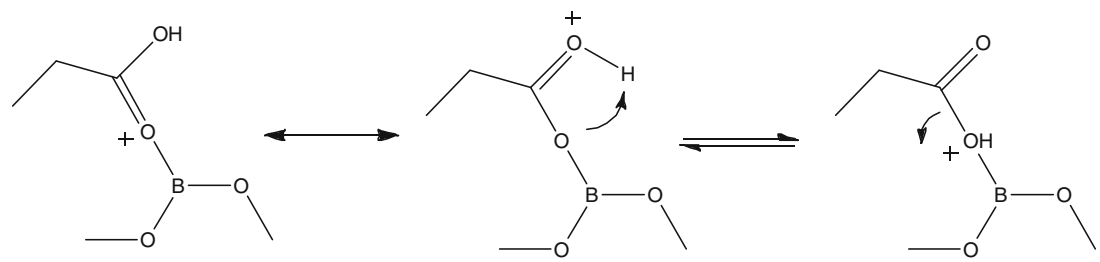

$(\mathrm{MeO})_{2} \mathrm{BOH}$ Loss

Scheme 5. Mechanism for elimination of dimethyl borate upon reaction of a protonated propanoic acid with TMB 
BOH (Table 3), just like in the FT-ICR. Based on literature [37], methanol elimination also occurs for aromatic ketones in LQIT but they also eliminate $\mathrm{O}=\mathrm{BOCH}_{3}$ and $\mathrm{O}=\mathrm{BOCH}_{3}+\mathrm{CH}_{2} \mathrm{O}$, and hence can be distinguished from vinyl and phenyl epoxides. Further, elimination of $\left(\mathrm{CH}_{3} \mathrm{O}\right)_{2} \mathrm{BOH}$ has been reported [37] in LQIT for the addition/methanol elimination product of cyclic ethers. Hence, the observation of not only methanol but also dimethyl ether elimination upon the ion/molecule reactions of protonated epoxides with TMB is important since it allows the differentiation of these analytes.

\section{Conclusions}

Gas-phase ion/molecule reactions of protonated epoxides with $\mathrm{TMB}$, followed by CAD, have been demonstrated to facilitate the identification of the epoxide functionalities in different ion trap mass spectrometers. Protonated analytes with oxygencontaining functionalities react with TMB by addition/methanol elimination in both FT-ICR and LQIT ion trap mass spectrometers. Upon SORI-CAD (FT-ICR) or CAD (LQIT), the product ions derived from vinyl and phenyl epoxides yield a fragment ion via elimination of a methanol molecule, which allows for the differentiation of these epoxides from other epoxides and other oxygen-containing functionalities. Product ions derived from some amides were earlier found [21] to undergo elimination of methanol upon SORI-CAD. However, these ions also undergo elimination of $\mathrm{O}=\mathrm{BR}\left(\mathrm{R}=\mathrm{H}, \mathrm{CH}_{3}\right.$ and $\mathrm{C}_{2} \mathrm{H}_{5}$ for formamide, acetamide and propionamide, respectively), which allows the differentiation of amides from vinyl and phenyl epoxides. Other epoxides can be differentiated from vinyl and phenyl epoxides and other oxygen-containing molecules based on the loss of $\left(\mathrm{CH}_{3} \mathrm{O}\right)_{2} \mathrm{BOH}$ or formation of protonated $\left(\mathrm{CH}_{3} \mathrm{O}\right)_{2} \mathrm{BOH}$ upon $\mathrm{CAD}$ of the addition/methanol elimination product formed upon reaction with TMB. The only other analytes found to fragment via loss of $\left(\mathrm{CH}_{3} \mathrm{O}\right)_{2} \mathrm{BOH}$ are carboxylic acids, which can be differentiated from all other analytes by literature methods $[20,27]$.

\section{Acknowledgments}

The authors acknowledge support for this work as part of the Center for Direct Catalytic Conversion of Biomass to Biofuels (C3Bio), an Energy Frontier Research Center funded by the U. S. Department of Energy, Office of Science, Office of Basic Energy Sciences under Award Number DE-SC0000997.

\section{References}

1. Luik, H., Johannes, I., Palu, V., Luik, L., Kruusement, K.: Transformation of Biomass Internal Oxygen at Varied Pyrolysis Conditions. J. Anal. Appl. Pyrol. 79, 121-127 (2007)

2. Kwon, K.C., Mayfield, H., Marolla, T., Nichols, B., Mashburn, M.: Catalytic Deoxygenation of Liquid Biomass for Hydrocarbon Fuels. Renew. Energ. 36, 907-915 (2011)
3. Peiris, D.M., Lam, W., Michael, S., Ramanathan, R.: Distinguishing $N$-oxide and Hydroxyl Compounds: Impact of Heated Capillary/ heated Ion Transfer Tube in Inducing Atmospheric Pressure Ionization Source Decompositions. J. Mass Spectrom. 39, 600606 (2004)

4. Winger, B.E., Kemp, C.A.J.: Characterization of Pharmaceutical Compounds and Related Substances by Using HPLC FTICR-MS and Tandem Mass Spectrometry. Am. Pharm. Rev. 4, 55-63 (2001)

5. de Hoffmann, E.: Tandem Mass Spectrometry: a Primer. J. Mass Spectrom. 31, 129-137 (1996)

6. McLafferty, F.W.: Tandem Mass Spectrometry (MS/MS): A Promising New Analytical Technique for Specific Component Determination in Complex Mixtures. Am. Chem. Soc. 13, 33-39 (1980)

7. Schroeder, M.J., Shabanowitz, J., Schwartz, J.C., Hunt, D.F., Coon, J.J.: A Neutral Loss Activation Method for Improved Phosphopeptide Sequence Analysis by Quadrupole Ion Trap Mass Spectrometry. Anal. Chem. 76(13), 3590-3598 (2004)

8. Levsen, K., Schwarz, H.: Gas-Phase Chemistry of Collisionally Activated Ions. Mass Spectrom. Rev. 2, 77-148 (1983)

9. Kenttämaa, H.I., Pachuta, R.R., Rothwell, A., Cooks, R.G.: ExperimentalStudy of the Potential-Energy Surface of the Protonated Cyclohexene Oxide Cyclohexanone System-Isomerization, Dissociation, and Ion Molecule Reactions of the Isolated Ions in the Gas-Phase. J. Am. Chem. Soc. 111, 1654-1665 (1989)

10. Brodbelt, J.S.: Analytical Applications of Ion-Molecule Reactions. Mass Spectrom. Rev. 16, 91-110 (1997)

11. Eichmann, E.S., Brodbelt, J.S.: Application of Site-Selective IonMolecule Reactions to the Analysis of the Cinchona Alkaloids. Org. Mass Spectrom. 28, 1608-1615 (1993)

12. Alvarez, E.J., Brodbelt, J.S.: Selective Ion-Molecule Reactions of Ether Reagent Ions with Nucleoside Antibiotics in a Quadrupole Ion Trap. J. Mass Spectrom. 30, 625-631 (1995)

13. Ramos, L.E., Cardoso, A.M., Correia, A.J.F., Nibbering, N.M.M.: Behavior of Arylalkylamines Toward Trimethyl Borate as a Gas-Phase Reagent. Int. J. Mass Spectrom. 203, 101-110 (2000)

14. Moraes, L.A.B., Gozzo, F.C., Eberlin, M.N., Vainiotalo, P.J.: Transacetalization with Acylium Ions. A Structurally Diagnostic Ion/ Molecule Reaction for Cyclic Acetals and Ketals in the Gas Phase. J. Org. Chem. 62, 5096-5103 (1997)

15. Eberlin, M.N.: Structurally Diagnostic Ion/Molecule Reactions: Class and Functional-Group Identification by Mass Spectrometry. J. Mass Spectrom. 41, 141-156 (2006)

16. Meurer, E.C., Chen, H., Riter, L.S., Cooks, R.G.: Meerwein Reaction of Phosphonium Ions with Epoxides and Thioepoxides in the Gas Phase. $J$. Am. Soc. Mass Spectrom. 15, 398-405 (2004)

17. Ranatunga, T.D., Kenttämaa, H.I.: Gas-Phase Reactions of Dicoordicated Boron Cations with Alcohols. Inorg. Chem. 34, 18-27 (1995)

18. Ranatunga, T.D., Kennedy, J.M., Kenttämaa, H.I.: Disubstituted Boron Cleave Carbonyl Bonds. J. Am. Chem. Soc. 119, 5200-5207 (1997)

19. Kempen, E.C., Brodbelt, J.: Use of Trimethyl Borates as a Chemical Ionization Reagent for Analysis of Biologically Active Molecules. J. Mass Spectrom. 32, 846-854 (1997)

20. Watkins, M.A., Price, J.M., Winger, B.E., Kenttämaa, H.I.: IonMolecule Reactions for Mass Spectrometric Identification of Functional Groups in Protonated Oxygen-Containing Monofunctional Compounds. Anal. Chem. 76, 964-976 (2004)

21. Watkins, M.A., Winger, B.E., Shea, R.C., Kenttämaa, H.I.: IonMolecule Reactions for the Characterization of Polyols and Polyol Mixtures by ESI/FT-ICR Mass Spectrometry. Anal. Chem. 77, 13851392 (2005)

22. Somuramasami, J., Duan, P., Watkins, M.A., Winger, B.E., Kenttämaa, H.I.: Ion-Molecule Reactions of Trimethylborate Allow the Mass Spectrometric Identification and Counting of Functional Groups in Protonated Bifunctional Oxygen-Containing Compounds and Polyols. Int. J. Mass Spectrom. 265, 359-371 (2007)

23. Campbell, K.M., Watkins, M.A., Li, S., Fiddler, M.N., Winger, B., Kenttämaa, H.I.: Functional Group Selective Ion/Molecule Reactions: Mass Spectrometric Identification of the Amido Functionality in Protonated Monofunctional Compounds. J. Org. Chem. 72, 31593165 (2007)

24. Gronert, S., O’Hair, R.A.J.: Gas Phase Reactions of Trimethyl Borate with Phosphates and Their Noncovalent Complexes. J. Am. Soc. Mass Spectrom. 13, 1088-1098 (2002) 
25. Ranatunga, T.D., Kenttämaa, H.I.: Dicoordinated Boron Cations Dehydrate Organic Ethers in the Gas-Phase. J. Am. Chem. Soc. 114, 8600-8604 (1992)

26. Suming, H., Yaozu, C., Longfei, J., Shuman, X.: Stereochemical Effects in Mass Spectrometry. Org. Mass Spectrom. 20, 719 (1985)

27. Habicht, S.C., Vinueza, N.R., Archibold, E.F., Duan, P., Kenttämaa, H.I.: Identification of the Carboxylic Acid Functionality by Using Electrospray Ionization and Ion-Molecule Reactions in a Modified Linear Quadruple Ion Trap Mass Spectrometer. Anal. Chem. 80, 3416-3421 (2008)

28. Dunbar, R.C.: Infrared Radiative Cooling of Gas-Phase Ions. Mass Spectrom. Rev. 11, 309-339 (1992)

29. Chen, L., Wang, T.C.L., Ricca, T.L., Marshall, A.G.: Phase-Modulated Stored Wave-Form Inverse Fourier-Transform Excitation for Trapped Ion Mass-Spectrometry. Anal. Chem. 59, 449-454 (1987)

30. Marshall, A.G., Wang, T.C.L., Ricca, T.L.: Tailored Excitation for Fourier Transform Ion Cyclotron Mass Spectrometry. J. Am. Chem. Soc. 107, 7893-7897 (1985)

31. Gauthier, J.W., Trautman, T.R., Jackson, D.B.: Sustained Off-Resonance Irradiation for Collision-Activated Dissociation Involving Fourier Trans- form Mass Spectrometry. Collision-Activated Dissociation Technique that Emulates Infrared Multiphoton Dissociation. Anal. Chim. Acta 246, 211225 (1991)

32. Gronert, S.: Estimation of Effective Ion Temperature in a Quadrupole Ion Trap. J. Am. Soc. Mass Spectrom. 9, 845-848 (1998)

33. Gronert, S.: Quadrupole Ion Trap Studies of Fundamental Organic Reactions. Mass Spectrom. Rev. 24, 100-120 (2005)

34. Schwartz, J.C., Senko, M.W., Syka, J.E.P.: A Two-Dimensional Quadrupole Ion Trap Mass Spectrometer. J. Am. Soc. Mass Spectrom. 13, 659-669 (2002)

35. Satterfield, M., Brodbelt, J.S.: Site of Reaction of Pilocarpine. J. Am. Mass. Spectrom. 10, 209-216 (1999)

36. Hunter, E.P., Lias, S.G.: Evaluated Gas Phase Basicities and Proton Affinities of Molecules: An Update. J. Phys. Chem. Ref. Data 27, 413656 (1998)

37. Habicht, S.C., Vinueza, N.R., Amundson, L.M., Kenttämaa, H.I.: Comparison of Functional Group Selective Ion-molecule Reactions of Trimethyl Borate in Different Ion Trap Mass Spectrometers. J. Am. Soc. Mass Spectrom. 22, 520-530 (2011) 